\title{
The prenatal environment and type 1 diabetes
}

\author{
L. C. Stene • E. A. M. Gale
}

Received: 14 November 2012 / Accepted: 15 April 2013 /Published online: 10 May 2013

(C) Springer-Verlag Berlin Heidelberg 2013

\begin{abstract}
There is ample evidence that environmental factors are involved in the aetiology of type 1 diabetes, but the nature and timing of the interactions are poorly understood. The intrauterine environment is known to play a role in the later development of type 2 diabetes, and this review considers a possible role in type 1 diabetes. Autoimmune type 1 diabetes is rare in those diagnosed before 6 months of age, but endogenous autoantibodies predictive of future type 1 diabetes may be detectable by 6-12 months of age, suggesting that environmental factors may operate before this age in some cases. Indirect evidence of a protective effect for the intrauterine environment comes from the observation that mothers with type 1 diabetes are less likely than affected fathers to transmit diabetes to their offspring, although the precise role (if any) is unclear. The risk of childhood-onset type 1 diabetes increases with maternal age at delivery, and with high birthweight, but these associations are weak and heterogeneous, and these factors are unlikely to be directly causally related to type 1 diabetes. No firm conclusion can be drawn from studies of maternal enteroviral infection or from various nutritional exposures. The birth process itself may play a role, as suggested by the slightly increased risk in children born by Caesarean section; lack of contact with maternal bacteria is one suggested mechanism. In sum, there is circumstantial evidence, but no proof of principle, that maternal or intrauterine conditions
\end{abstract}

L. C. Stene $(\bowtie)$

Division of Epidemiology, Norwegian Institute of Public Health, P.O. Box 4404 Nydalen, NO-0403 Oslo, Norway

e-mail: lars.christian.stene@fhi.no

\section{C. Stene}

Oslo Diabetes Research Centre, Oslo University Hospital, Oslo, Norway

E. A. M. Gale

Diabetes and Metabolism, Learning and Research, Southmead Hospital, Bristol BS10 5NB, UK may modulate genetic risk of type 1 diabetes. The disease process culminating in type 1 diabetes typically begins in early life, but it is not clear whether the trail begins before or after birth.

Keywords Aetiology $\cdot$ Maternal factors $\cdot$ Non-genetic factors $\cdot$ Prenatal environment $\cdot$ Review $\cdot$ Risk factors $\cdot$ Type 1 diabetes
Abbreviations
DHA Docosahexaenoic acid
DIPP Diabetes Prediction and Prevention
EPA Eicosapentaenoic acid

\section{Introduction}

'Perinatal' factors such as birth order and maternal age at delivery have long been investigated in studies of the aetiology of various postnatal traits such as intelligence [1], but the idea that chronic diseases that typically present in adult life, such as cancer and diabetes, might originate in utero is only slowly gaining acceptance $[2,3]$. Although the mechanisms remain poorly defined, an association between low birthweight and increased risk of type 2 diabetes is now fairly well established [2]. Curiously, a high birthweight $(>4 \mathrm{~kg}$ ), appears to be associated with an increased risk of childhood-onset type 1 diabetes [4, 5], as discussed below. The intrauterine environment has also been proposed to influence the development of the immune system and risk of atopic disorders in children [6-8].

Although there is compelling evidence that genetic factors determine susceptibility to type 1 diabetes, many lines of evidence, including the rapidly rising incidence of the condition, indicate an important role for non-genetic factors $[9,10]$. Nevertheless, no single environmental factor has as yet been convincingly implicated in the aetiology of the 
condition. One possible reason for this is that environmental influences may operate through a transient window of opportunity in early development, long before the disease or even early markers of the disease process become manifest. In theory at least, such influences could act (1) to initiate the disease before potentially harmful immune responses have been activated; (2) to promote (or delay) the progression of an established immune response leading to overt diabetes; or (3) to precipitate diabetes in those with incipient beta cell failure.

Recent reviews have considered the potential roles of postnatal environmental exposures in the aetiology of type 1 diabetes, including dietary factors such as infant feeding $[11,12]$, postnatal growth $[13,14]$, viral infections $[15,16]$, gut microbiota [17] and toxins [18]. Here, we review evidence concerning possible links between the prenatal environment and the later development of immune-mediated diabetes.

\section{Natural history of type 1 diabetes}

In type 1 diabetes the pancreatic beta cells are selectively destroyed by the immune system, and autoreactive $\mathrm{T}$ cells are thought to be responsible [19]. The details of these mechanisms are complex and beyond the scope of this review. A large number of genetic susceptibility loci have been identified, generally with very weak effects [20]. The exception is the HLA genes, which play a major role in the aetiology of type 1 diabetes [21]. In recent years, the proportion of children with new-onset type 1 diabetes who carry the highest risk (DR4-DQ8/DR3-DQ2) genotype has decreased in many populations $[22,23]$. This suggests that unidentified changes in the environment have contributed to a higher penetration of 'permissive' genotypes.

Islet autoantibodies directed against insulin, glutamic acid decarboxylase, islet antigen 2 (also referred to as IA-2 or protein tyrosine phosphatase, receptor type, N) or zinc transporter 8 generally appear in the circulation years before clinical onset, and can be detected in $\sim 90 \%$ of individuals at diagnosis $[19,24,25]$. Current evidence suggests that these are not directly involved in beta cell killing, although it has been controversially suggested that anti-idiotypic antibodies protect healthy humans from autoimmunity, and that a lack of these may permit islet autoantibodies to be become pathogenic [26].

While continuing to mature throughout gestation and during the postnatal period, the beta cells [27] and an immune system capable of targeting them [28, 29] are functional in the fetus by around mid-gestation. Nevertheless, classical autoimmune type 1 diabetes is probably never expressed in neonates and is rarely responsible for diabetes presenting under the age of 6 months. In accordance with general immunological principles, it is therefore possible that the fetus somehow promotes a state of tolerance [30]. Islet autoantibodies can sometimes be detected in umbilical cord blood, and conflicting data on the importance of these have been published [31-33]. While more high-quality studies in this field are welcome, the available data from humans suggest that islet autoantibodies in cord blood are usually transplacentally transferred from the mother and are not associated with an increased risk of type 1 diabetes in the child [33, 34]; indeed the largest study of maternal islet autoantibodies suggests they may in fact be associated with a lower risk in the offspring [33].

In birth cohort studies, seroconversion for diseasepredictive islet autoantibodies has occasionally been shown to occur before 6 months of age [35]. Long-term follow-up has shown a peak incidence of seroconversion for islet autoantibodies at around 9-18 months of age, and most of those who progress to type 1 diabetes during childhood express islet autoantibodies before 2-4 years of age [24, 25].

Although current evidence suggests that seroconversion for clinically relevant islet autoantibodies is a postnatal phenomenon, it is nevertheless possible that events taking place before or shortly after birth have the potential to influence the later development of islet autoimmunity and type 1 diabetes. The mechanisms involved are unknown, but some general possibilities are listed in the text box [36-38], and some are discussed in more detail below.

\section{Twin and other family studies}

Risk of recurrence in dizygotic twins vs non-twin sibships Because non-twin sibling pairs and dizygotic twin pairs both share $50 \%$ of their genes, a higher risk in individuals with an affected dizygotic twin compared with that in individuals with an affected non-twin sibling would indicate that the intrauterine environment or shared early life environment influences the risk of disease, assuming that twinning and birth order are not themselves associated with risk. Available risk estimates for recurrence in dizygotic twins [39-43] tend to be somewhat higher than most risk estimates for non-twin sibships [44, 45], and this difference was greatest in a recent study from Italy [39]. However, such twin estimates are imprecise and vary between studies, and directly comparable estimates for non-twin sibships are not available. More large-scale studies in this field are therefore necessary before we can draw firm conclusions.

Risk in offspring of fathers vs mothers with type 1 diabetes Warram et al first made the curious observation that maternal disease was associated with lower risk of type 1 diabetes in the offspring than was paternal type 1 diabetes [46], later confirmed by many others [47-49]. The underlying mechanism is unknown, but a role of the intrauterine 


\section{Some general mechanisms by which the intrauterine and early neonatal environment may influence the fetus/offspring with potential long-term effects}

\section{At conception}

- Maternal and paternal genes

- Genes inherited by the fetus may operate in utero or postnatally. Fetal genetic polymorphisms in the INS locus are thought to influence expression of the INS gene in the fetal thymus and thereby the selection of insulin reactive $\mathrm{T}$ cells and later development of type 1 diabetes [36]

- Non-inherited maternal DNA sequences may theoretically influence the intrauterine environment. The literature on non-inherited maternal HLA alleles shows mixed results, with no evidence in the type 1 diabetes genetics consortium [37, 38]

- Epigenetic factors

- In addition to genes inherited from the mother and father, the fertilised egg contains maternal (egg cell) cytoplasm with mitochondria, mRNA, proteins, nutrients and other molecules from the mother, potentially including persistent environmental toxins. These may dictate DNA methylation patterns and other epigenetic mechanisms transmitting information into postnatal life

\section{Intrauterine life}

- Transplacental transfer. Nutrients, metabolites, and other molecules, possibly including toxins and microbes, are transported from the mother passively or actively over the placenta to the fetus

- Maternal antibodies of the immunoglobulin G class are actively transported across the placenta. This provides the fetus with temporary, passive protection against pathogens in the environment. Maternal autoantibodies may also be transferred (see main text)

- A few maternal cells, including haematopoietic stem cells, are transferred from the mother to the fetus. These may persist in fetal tissues for years, but the function of this phenomenon is only beginning to be explored (see separate section on maternal microchimerism in the main text)

- Fetal swallowing. The fetus swallows large amounts of amniotic fluid, which contains a small amount of nutrients, immunoglobulins, cytokines, hormones and growth factors such as insulin, which may influence the fetal gut and gut-associated immune system

\section{Parturition}

- Contamination with blood and microbes

environment has been proposed, for example, stimulation of beta cell growth and maturation by maternal hyperglycaemia. $\mathrm{HbA}_{1 \mathrm{c}}$ during pregnancy in women with type 1 diabetes does, however, suggest a U-shaped relationship with risk of islet autoimmunity or type 1 diabetes in the offspring in the German BABYDIAB study [50], which is not easy to explain in relation to this hypothesis. Most familial aggregation studies show that relatives of patients with early-onset disease are themselves at higher risk of early-onset disease, as might be expected because of a stronger genetic contribution [51, 52], but not all data regarding age of onset in mothers are consistent. Harjutsalo et al recently found no association between age at onset in affected mothers and risk of type 1 diabetes in offspring, and noted that the higher risk associated with paternal type 1 diabetes was only observed when parents contracted type 1 diabetes during childhood [53]. Other studies have reported similar patterns, albeit not statistically significant ones $[47,54]$, whereas a clinic-based study from the USA reported a higher risk for offspring of mothers with very early onset but no association with paternal age at onset [55]. Studies of the offspring of mothers who developed type 1 diabetes before or after pregnancy might help to dissect out the relative contribution of the intrauterine environment compared with inherited mechanisms, but the relative rarity of pregnancy in adult-onset diabetes and the need to control for differences in age at onset would make such a study difficult to perform [47].

\section{Maternal age, birthweight, Caesarean section and related perinatal factors}

Systematic reviews and individual patient data analyses of perinatal factors and risk of type 1 diabetes in recent years have involved more than 20 studies and up to 10,000 cases of type 1 diabetes. Weak, heterogeneous but overall statistically significant associations with risk of diabetes in the offspring have been found for Caesarean section, birthweight and maternal age at delivery (Fig. 1) [5, 56-61]. Many of the individual studies 


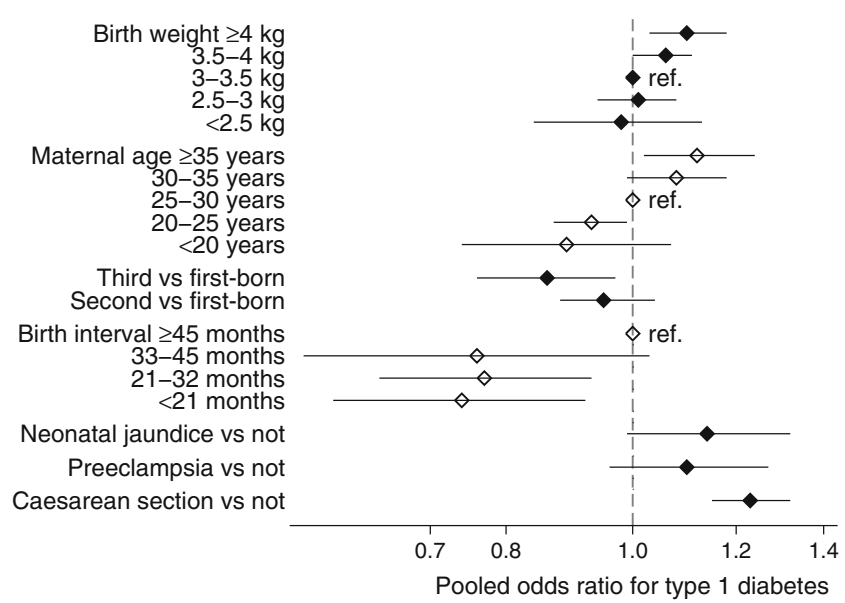

Fig. 1 Odds ratios with $95 \%$ confidence intervals for associations of perinatal factors and risk of type 1 diabetes based on a series of metaanalyses after systematic reviews by Cardwell and colleagues [5, 56-61]. Each topic included 14-31 independent studies with a total of approximately 10,000 cases of type 1 diabetes for most study factors. Estimates adjusted for all available covariates are shown for maternal age and birth interval, and birth order estimates were adjusted for maternal age only. For other factors, adjustment for a range of potential confounders led to little change in estimates or slightly stronger associations, and unadjusted estimates are shown for these

included in the pooled analyses did not demonstrate significant results by themselves, and in many cases the direction of the association was not consistent across studies. Most original studies used a case-control design, which is susceptible to selection bias and sometimes to recall bias, but most results tended to be consistent in the few, albeit large, cohort studies. A few longitudinal studies of genetically susceptible children have also investigated some of these factors in relation to the development of islet autoantibodies. This is an interesting strength of such longitudinal studies, but the number of children with islet autoimmunity in these has generally been much lower than that in studies with clinical type 1 diabetes as the endpoint $[62,63]$. These perinatal factors are most likely proxies for other related but unidentified environmental exposures that may play different roles in different populations, and the main value of these studies lies in hypothesis generation. A number of other routinely recorded perinatal factors have also been studied in relation to type 1 diabetes, but most have shown no consistent association.

Maternal age at delivery and birth order Studies of varying design relating maternal age and birth order to type 1 diabetes were carried out between the 1960s and 1990s [64-67]. The pooled analysis of newer studies showed heterogeneity in the strength of the association, but most suggested increased risk among the offspring of mothers who were older when they gave birth [57]. No satisfactory explanation has been proposed, but we can speculate that maternal age may be a marker of some kind of accumulated maternal exposure.
The association with paternal age, independent of maternal age and birth order, has not been systematically reviewed. A few studies have found such an independent positive association, while others have not. In rodents, parental diet has been shown to influence the degree of DNA methylation, levels of micro RNA and gene expression (mRNA) in the tissues of offspring [68, 69]. While the relevance in human type 1 diabetes is unknown, this provides a possible mechanism for paternal non-genetic influence on the offspring. The potential role of epigenetic mechanisms in type 1 diabetes is discussed in some more detail below.

The 'hygiene hypothesis' is usually attributed to Strachan, who found that eczema and hay-fever were less common in children with older siblings in the household [70]. The author suggested that this was explained by greater exposure to infections contracted by their siblings in the early neonatal period, but he did not consider other potential factors. Although an attractive hypothesis, for type 1 diabetes this has not been further supported by analyses of specific infection or more direct estimates of exposure to other children in individual-level epidemiological studies. In theory, prenatal mechanisms such as maternal immunity could be involved in the birth order association with type 1 diabetes, such as immunity to paternal tissue antigens or other forms of altered feto-maternal immune response with successive pregnancies. However, birth order associations with type 1 diabetes are weak and heterogeneous [58], suggesting that the effect may be minor, non-existent or confounded by other factors. The recent observation that children born to mothers after short $(<3$ years) inter-birth intervals have a lower risk of type 1 diabetes than children born after longer intervals should also be explored further [59].

Caesarean section Caesarean section is associated with a relative risk for type 1 diabetes of approximately 1.2, with variation among studies [56]. Recent results from the German BABYDIAB study suggest that Caesarean section is not associated with risk of islet autoantibodies, but is associated with risk of progression from islet autoimmunity to clinical type 1 diabetes [71]. This should be replicated in other longitudinal studies. Regardless of whether the association is primarily with islet autoimmunity or with progression from islet autoimmunity to clinical type 1 diabetes, the underlying mechanism is unknown. A possible explanation involves an alteration in the timing and composition of the infant gut microbiota following Caesarean section [72], but this remains speculative [17].

Size and gestational age at birth Pooled analysis suggested a weak, statistically significant but heterogeneous positive association between birthweight and type 1 diabetes, independent of maternal diabetes [5]. Data from offspring of 
women with type 1 diabetes are probably not comparable to those in the general population, but such data from the German BABYDIAB study suggested an inverted Ushaped relationship between birthweight and risk of islet autoimmunity or type 1 diabetes [50]. Confounding by genetic polymorphisms such as HLA and INS has been proposed, but the evidence does not seem to support a genetic explanation for the association between high birthweight and type 1 diabetes in the general population [73]. Shorter gestational duration is also weakly but significantly associated with risk for type 1 diabetes [4, 56, 67]. The mechanisms have not been elucidated, but it has been speculated that high birthweight or rapid postnatal growth is associated with higher insulin secretion, which might, according to in vitro evidence, render the beta cells more susceptible to damage [74]. Since both perinatal body size and growth seem to be associated with obesity later in life, as well as the timing of puberty, subtle modulation of insulin secretion and action might mediate the association between perinatal body size or growth and later risk of type 1 diabetes [75].

Maternal smoking in pregnancy Dahlquist and Källén noted an unexpected association between maternal smoking during pregnancy and reduced risk of type 1 diabetes [67]. The topic has never been systematically reviewed, but we identified at least 11 additional studies presenting data on this association in a comprehensive search, albeit with large heterogeneity in resolution and quality of data. Results were once again heterogeneous, but studies in which the information on maternal smoking in pregnancy was registered before or soon after birth (rather than by retrospective recall) tended to be consistent with the initial observation by Dahlquist and Källén [76-79]. We identified published data from four birth cohort studies with longitudinal follow-up for islet autoantibodies [62, 63, 80, 81]. While the total number of cases was only 244 , and none of the studies showed significant associations, the point estimates for the relative risk appeared quite homogeneous at about 0.5 to 0.7. Maternal smoking might influence some aspects of immune function [82] and DNA methylation [83] in the offspring, but the suggestive association between maternal smoking in pregnancy and lower risk of type 1 diabetes in the offspring should be interpreted with caution because of the many possible sources of error, not to mention the public health hazards of smoking.

\section{Intrauterine infections}

The historical example of congenital rubella infection and risk of diabetes Congenital rubella is due to infection of a non-immune mother during pregnancy and viraemia of the unprotected fetus. The syndrome is variable in its presentation owing to variation in the timing and severity of infection, but features include low birthweight, deafness and mental retardation. In a 25 year review of patients with congenital rubella who were born around 1940, one of 50 patients was found to have undiagnosed diabetes [84] and further cases were later reported [85]. Rubella virus has also been recovered from the pancreas of infected children. It is often stated that approximately $10-20 \%$ of individuals affected by the congenital rubella syndrome have diabetes $[85$, 86], but a number of other studies indicate a much lower risk. Furthermore, the patients in the reports included adults with impaired glucose tolerance and diabetes not treated with insulin, or the clinical characteristics were poorly described (see [9, 87] for original references). Some patients may have had typical features of type 1 diabetes, but many were atypical, and possible alternative causes of hyperglycaemia included persistent viraemia, low birthweight and pancreatic dysgenesis. Congenital rubella is now prevented by routine immunisation in most parts of the world, and the real answer may never be known. We conclude that rubella virus provides proof of concept that intrauterine infection can predispose to diabetes later in life, but that the evidence linking it to (or providing a model of) type 1 diabetes is inconclusive.

Intrauterine enterovirus infections In some studies maternal enterovirus infections have also been reported to be associated with type 1 diabetes. Inconsistent findings have also been reported, mostly from small to moderate size studies using various methods [15]. The largest study to date suggested a moderate association between serological evidence for maternal enterovirus during pregnancy and increased risk of type 1 diabetes in children [88]. The potential roles of postnatal enterovirus and other virus infections have been extensively reviewed elsewhere [16], including plausible mechanisms involved, and this will not be covered here. Methodological difficulties complicate interpretation of the data on intrauterine enterovirus and other virus infections, and once again no certain conclusions can be drawn.

\section{Intrauterine nutrition}

Several aspects of early-life nutrition have been suggested to influence the risk of islet autoimmunity or type 1 diabetes, and potential mechanisms have been reviewed [11]. General aspects of maternal diet during pregnancy such as intake of different foods and nutrients have been tested for association with islet autoimmunity or type 1 diabetes in the offspring in explorative analyses of longitudinal birth cohort studies, but convincing associations have not emerged to date $[89,90]$. 
Maternal long-chain n-3 fatty acids and vitamin D A retrospective survey reported that mothers of children with type 1 diabetes consumed less cod liver oil during pregnancy [91]. Prospective studies including biomarkers are to be preferred, since these minimise the role of recall and selection bias. Cod liver oil is rich in vitamin $\mathrm{D}$ and the long-chain $n-3$ fatty acids docosahexaenoic acid (DHA) and eicosapentaenoic acid (EPA) are thought to have anti-inflammatory properties. A prospective study of DHA, EPA and other fatty acids in the phospholipid fraction of maternal serum collected in late pregnancy found no association with risk of type 1 diabetes before 15 years of age [92], although possible degradation of polyunsaturated fatty acids during storage of samples could not be excluded. Using a lipidomics approach in the Diabetes Prediction and Prevention (DIPP) study, Oresic et al found that some lipid species differed systematically in blood samples from birth until seroconversion in children who progressed to type 1 diabetes as compared with controls [93]. Further studies of this type are under way.

Vitamin D status during the intrauterine period may be of special importance for development of the fetus [94]. The decidual and trophoblastic cells in the placenta produce 1- $\alpha$ hydroxylase, and plasma levels of the normally tightly controlled active form of vitamin D (1,25-dihydroxyvitamin D) are usually higher during gestation [95]. The few studies performed to date relating maternal vitamin $\mathrm{D}$ to type 1 diabetes in the offspring have reached mixed conclusions. Maternal dietary intake of vitamin D from food or supplements was not associated with islet autoimmunity or type 1 diabetes in the DIPP study [96]. A Norwegian study found an association between higher serum 25-hydroxyvitamin D in samples collected in late pregnancy and lower risk of type 1 diabetes in the offspring [97], whereas a Finnish study found no such association with samples collected in the first trimester of pregnancy [98]. It remains to be seen whether these conflicting results were due to differences in sampling time, analysis or other factors.

\section{Experimental evidence}

Evidence discussed so far has been observational, and results must be interpreted with due attention to potential confounding, measurement error and selection bias. In practice, confounding can only be controlled in randomised (experimental) studies, but such studies often suffer from selection bias, limited sample size and limited contrast in exposure, resulting in low statistical power. Not all exposures can be randomised for ethical or practical reasons, but many can - although some ingenuity may be required [99-101]. We are not aware of on-going randomised studies of prenatal factors powered to investigate effects on islet autoimmunity or type 1 diabetes.
A few animal studies have also tested the potential role of the perinatal environment in relation to risk of autoimmune diabetes, although such results cannot necessarily be extrapolated to humans. Complete depletion of vitamin D in NOD mice during intrauterine and early life led to a higher cumulative incidence of diabetes [102], but vitamin D supplements in utero or in early life (in addition to the vitamin D in normal mouse chow) made no difference [103].

Dietary energy restriction in pregnant NOD mice reduced birthweight and incidence of diabetes in the offspring [104], in keeping with observed associations with birthweight in humans. NOD embryos implanted into the uterus of pseudopregnant surrogate mothers of other strains (DBA/2) had a significantly lower incidence of diabetes compared with NOD progeny implanted into NOD surrogate mothers [32]. The authors suggest that maternal islet autoantibodies might be responsible for these differences [32], but this is contrary to the human experience [33], and other factors might well be involved.

\section{Some mechanisms of potential relevance}

Maternal microchimerism A few maternal cells enter the fetal circulation and are recognised as 'self'. These can persist for many years in healthy individuals [105]. In theory, a single $\mathrm{T}$ cell clone that is potentially reactive towards the (foreign, non-self) fetal beta cells may be transmitted from the mother and later expand and cause disease. Alternatively, maternal stem cells integrated in fetal/ offspring islet tissue might potentially be recognised as alien and attacked by the offspring's immune system, although healthy children are tolerant to genetically distinct maternal cells. It has recently been shown that substantial numbers of maternal cells reside in fetal lymph nodes, inducing the development of $\mathrm{CD}^{+} \mathrm{CD}^{+} 5^{\text {high }} \mathrm{FoxP}^{+} \mathrm{T}$ regulatory cells that suppress fetal anti-maternal immunity and persist for many years [106].

Studies of patients with recent-onset type 1 diabetes have identified a higher number of maternal cells in the periphery and in the pancreas compared with controls [107, 108]. Maternal cells in the islets of deceased patients with recent-onset type 1 diabetes did not have an immune origin, which argues against activation of maternal immune cells [108]. One hypothesis is that the increased numbers of maternally derived cells are due to an attempt to replace beta cells lost to as a result of immune attack [107]. The potential role of maternal microchimerism in type 1 diabetes remains to be determined.

Epigenetics Epigenetics is an evolving concept that concerns molecular factors and processes, independent of DNA sequence, but which influence gene expression and 
are stable over at least a few cell divisions. Here, we can only give a brief introduction to the field, and we refer the reader to the cited references for more details.

There is increasing evidence for the involvement of epigenetic factors in differentiation of $\mathrm{T}$ helper cells into various subtypes, and chemical modification of histone tails influencing chromatin and accessibility of transcription factors appears to play a role in many regulatory processes over relatively short periods of time. MacFarlane et al recently reviewed epigenetic mechanisms potentially influencing the risk of type 1 diabetes [109].

DNA methylation is thought to be involved in transmitting information from the intrauterine environment to regulate the processes involved in various aspects of later health and disease, and probably also plays a role in transmitting intergenerational effects of environmental exposures [110]. Recent pilot data from a randomised trial in the Gambia suggested that pre- and peri-conceptional maternal micronutrient supplementation could influence DNA methylation in the offspring with some effects being expressed at 9 months of age and not at birth [111].

In rodent models, paternal diet and exposure to toxins have been shown to influence DNA methylation and expression of genes relevant for metabolism in the offspring. Information was therefore somehow transmitted via the sperm, but, at least in one study, apparently not via methylation pattern in the sperm DNA [69].

The role of epigenetics in the prediction and prevention of complex disease is still at an early phase of development [112]. In addition to increased understanding of the molecular factors and processes involved in human gene regulation from projects such as Encyclopedia of DNA Elements (ENCODE; www.nature.com/encode/\#/threads) and the International Human Epigenome Consortium (www.ihecepigenomes.org/), we will certainly see improvements in performance and reduction in the cost of available technologies to assay epigenetic factors in large-scale human studies in the near future. Population-based epigenome-wide association studies have only recently become feasible [113]. In principle, methylation pattern may to some degree be inherited, and available data suggest that the inheritance is relatively low but is variable across the genome. A low inheritance would be accordant with the idea that methylation pattern, at least at some loci, can be influenced by the environment. A study in monozygotic twins and a few individuals followed prospectively from before type 1 diabetes onset identified potentially differentially methylated regions in type 1 diabetes [114]. As DNA methylation is in principle time- and tissue-specific, differentially methylated regions identified in patients at or after diagnosis compared with controls may well arise as a consequence of disease (reverse causation). More prospective studies in this field are under way.

\section{Conclusions}

Despite some suggestive associations, there is no clear proof of principle that non-genetic prenatal factors have any direct influence upon the subsequent development of immune-mediated diabetes in humans or experimental animals. The evidence is circumstantial, most studies have (of necessity) been exploratory and the associations reported have generally been weak and inconsistent. Possible reasons for the inconsistency include methodological differences and confounding of intrauterine and postnatal exposures. Another possibility that has been little explored is gene-environment interactions, where the association depends on the presence of genetic susceptibility variants $[71,115]$. The markers of risk that have been identified may simply be proxies for other more important causal influences. Nonetheless, and in the absence of any strong or consistent signal, it is difficult to conclude that major prenatal influences are at work. The possibility cannot be altogether dismissed, however, since loss of tolerance to islet antigens undoubtedly develops very early in postnatal life, and the intrauterine environment might plausibly set the scene for such a development. Greater understanding of the ontogeny of the immune system before and after birth will be needed before this question can be answered with any confidence.

In our view, the available evidence does not currently support the initiation of randomised trials of preventive vaccines, dietary supplements or other agents during pregnancy to reduce the incidence of type 1 diabetes in offspring. Such trials will need to be based upon a much firmer body of evidence from observational studies in humans and, ideally, be backed by studies in experimental models. Longitudinal cohort studies such as The Environmental Determinants of Diabetes in the Young (TEDDY) study (www.teddystudy.org) and others will hopefully contribute to the evidence base needed to make such studies possible.

Acknowledgements L. C. Stene wishes to thank the Environmental Triggers of Type 1 Diabetes (MIDIA) research group (Norwegian Institute of Public Health, Oslo, Norway) and Kjersti S. Rønningen (Oslo University Hospital, Oslo, Norway), G. Joner (Oslo University Hospital, Oslo, Norway), M. Rewers (University of Colorado, Aurora, CO, USA) and C. Cardwell (University of Belfast, Belfast, UK) for stimulating collaboration and discussions. We apologise to the many authors of original research whose publications we could not cite owing to space restrictions.

Funding Research by L. C. Stene has been supported in part by the National Research Council of Norway.

Duality of interest The authors declare that there is no duality of interest associated with this manuscript. 
Contribution statement Both authors were responsible for the conception, design and drafting of the manuscript, and approved the final version for publication.

\section{References}

1. Galton F (1874) English men of science: their nature and nurture. Macmillan, London

2. Vaag AA, Grunnet LG, Arora GP, Brons C (2012) The thrifty phenotype hypothesis revisited. Diabetologia 55:2085-2088

3. Hoover RN, Hyer M, Pfeiffer RM et al (2011) Adverse health outcomes in women exposed in utero to diethylstilbestrol. N Engl J Med 365:1304-1314

4. Stene LC, Magnus P, Lie RT, Søvik O, Joner G, the Norwegian Childhood Diabetes Study Group (2001) Birth weight and childhood onset type 1 diabetes: population based cohort study. BMJ 322:889-892

5. Cardwell CR, Stene LC, Joner G et al (2010) Birthweight and the risk of childhood-onset type 1 diabetes: a meta-analysis of observational studies using individual patient data. Diabetologia 53:641-651

6. Prescott SL (2010) Allergic disease: understanding how in utero events set the scene. Proc Nutr Soc 69:366-372

7. Renz H, Brandtzaeg P, Hornef M (2012) The impact of perinatal immune development on mucosal homeostasis and chronic inflammation. Nat Rev Immunol 12:9-23

8. Warner JO (2006) Developmental origins of asthma and related allergic disorders. In: Gluckman P, Hanson M (eds) Developmental origins of health and disease. Cambridge University Press, Cambridge, pp 349-369

9. Stene LC, Tuomilehto J, Rewers M (2008) Global epidemiology of type 1 diabetes. In: Ekoé J-M, Rewers M, Williams R, Zimmet $P$ (eds) The epidemiology of diabetes mellitus, 2nd edn. WileyBlackwell, Chichester, pp 355-383

10. Knip M, Simell O (2012) Environmental triggers of type 1 diabetes. Cold Spring Harb Perspect Med 2:a007690

11. Knip M, Virtanen SM, Åkerblom HK (2010) Infant feeding and the risk of type 1 diabetes. Am J Clin Nutr 91:1506S-1513S

12. Cardwell CR, Stene LC, Ludvigsson J et al (2012) Breast-feeding and childhood-onset type 1 diabetes: a pooled analysis of individual participant data from 43 observational studies. Diabetes Care 35:2215-2225

13. Harder T, Roepke K, Diller N, Stechling Y, Dudenhausen JW, Plagemann A (2009) Birth weight, early weight gain, and subsequent risk of type 1 diabetes: systematic review and metaanalysis. Am J Epidemiol 169:1428-1436

14. Verbeeten KC, Elks CE, Daneman D, Ong KK (2011) Association between childhood obesity and subsequent type 1 diabetes: a systematic review and meta-analysis. Diabet Med 28:10-18

15. Stene LC, Rewers M (2012) Immunology in the clinic review series; focus on type 1 diabetes and viruses: the enterovirus link to type 1 diabetes: critical review of human studies. Clin Exp Immunol 168:12-23

16. Taylor KW, Hyöty H, Toniolo A, Zuckerman AJ (2012) Diabetes and viruses. Springer, New York

17. Atkinson MA, Chervonsky A (2012) Does the gut microbiota have a role in type 1 diabetes? Early evidence from humans and animal models of the disease. Diabetologia 55:2868-2877

18. Howard SG, Lee DH (2012) What is the role of human contamination by environmental chemicals in the development of type 1 diabetes? J Epidemiol Community Health 66:479-481

19. Bluestone JA, Herold K, Eisenbarth G (2010) Genetics, pathogenesis and clinical interventions in type 1 diabetes. Nature 464:1293-1300
20. Todd JA (2010) Etiology of type 1 diabetes. Immunity 32:457467

21. Noble JA, Erlich HA (2012) Genetics of type 1 diabetes. Cold Spring Harb Perspect Med 2:a007732

22. Hermann R, Knip M, Veijola R et al (2003) Temporal changes in the frequencies of HLA genotypes in patients with type 1 diabetes-indication of an increased environmental pressure? Diabetologia 46:420-425

23. Gillespie KM, Bain SC, Barnett AH et al (2004) The rising incidence of childhood type 1 diabetes and reduced contribution of high-risk HLA haplotypes. Lancet 364:1699-1700

24. Ziegler AG, Bonifacio E, the BABYDIAB-BABYDIET Study Group (2012) Age-related islet autoantibody incidence in offspring of patients with type 1 diabetes. Diabetologia 55:19371943

25. Parikka V, Näntö-Salonen K, Saarinen M et al (2012) Early seroconversion and rapidly increasing autoantibody concentrations predict prepubertal manifestation of type 1 diabetes in children at genetic risk. Diabetologia 55:1926-1936

26. Hampe CS (2012) Protective role of anti-idiotypic antibodies in autoimmunity-lessons for type 1 diabetes. Autoimmunity 45:320-331

27. Cleaver O, Melton DA (2005) Development of the endocrine pancreas. In: Kahn CR, Weir GC, King GL, Jacobson AM, Moses AC, Smith RJ (eds) Joslin's Diabetes Mellitus, 14th edn. Lippincott Williams \& Wilkins, Philadelphia, pp 22-39

28. Lewis DB, Wilson CB (2006) Developmental immunology and role of host defenses in fetal and neonatal susceptibility to infection. In: Remington JS, Klein JO, Wilson CB, Baker CJ (eds) Infectious diseases of the fetus and newborn infant, 6th edn Elsevier Saunders, Philadelphia, pp 87-210

29. PrabhuDas M, Adkins B, Gans H et al (2011) Challenges in infant immunity: implications for responses to infection and vaccines. Nat Immunol 12:189-194

30. Trowsdale J, Betz AG (2006) Mother's little helpers: mechanisms of maternal-fetal tolerance. Nat Immunol 7:241-246

31. Lindberg B, Ivarsson SA, Landin-Olsson M, Sundkvist G, Svanberg L, Lernmark $\AA$ (1999) Islet autoantibodies in cord blood from children who developed type I (insulin-dependent) diabetes mellitus before 15 years of age. Diabetologia 42:181187

32. Greeley SA, Katsumata M, Yu L et al (2002) Elimination of maternally transmitted autoantibodies prevents diabetes in nonobese diabetic mice. Nat Med 8:399-402

33. Koczwara K, Bonifacio E, Ziegler AG (2004) Transmission of maternal islet antibodies and risk of autoimmune diabetes in offspring of mothers with type 1 diabetes. Diabetes 53:1-4

34. Rewers M (2002) Islet autoantibodies in cord blood: maternal, fetal, or neither? Diabetes Metab Res Rev 18:2-4

35. Stene LC, Witsø E, Torjesen PA et al (2007) Islet autoantibody development during follow-up of high-risk children from the general Norwegian population from three months of age: design and early results from the MIDIA study. J Autoimmun 29:44-51

36. Pugliese A (2013) The multiple origins of type 1 diabetes. Diabet Med 30:135-146

37. Åkesson K, Carlsson A, Ivarsson SA et al (2009) The noninherited maternal HLA haplotype affects the risk for type 1 diabetes. Int J Immunogenet 36:1-8

38. Bronson PG, Ramsay PP, Thomson G, Barcellos LF (2009) Analysis of maternal-offspring HLA compatibility, parent-oforigin and non-inherited maternal effects for the classical HLA loci in type 1 diabetes. Diabetes Obes Metab 11(Suppl 1):74-83

39. Nistico L, Iafusco D, Galderisi A et al (2012) Emerging effects of early environmental factors over genetic background for type 1 diabetes susceptibility: evidence from a nationwide Italian twin study. J Clin Endocrinol Metab 97:E1483-E1491 
40. Condon J, Shaw JE, Luciano M, Kyvik KO, Martin NG, Duffy DL (2008) A study of diabetes mellitus within a large sample of Australian twins. Twin Res Hum Genet 11:28-40

41. Hyttinen V, Kaprio J, Kinnunen L, Koskenvuo M, Tuomilehto J (2003) Genetic liability of type 1 diabetes and the onset age among 22,650 young Finnish twin pairs: a nationwide followup study. Diabetes 52:1052-1055

42. Kyvik KO, Green A, Beck-Nielsen H (1995) Concordance rates of insulin dependent diabetes mellitus: a population based study of young Danish twins. BMJ 311:913-917

43. Kaprio J, Tuomilehto J, Koskenvuo M et al (1992) Concordance for type 1 (insulin-dependent) and type 2 (non-insulin-dependent) diabetes mellitus in a population-based cohort of twins in Finland. Diabetologia 35:1060-1067

44. Harjutsalo V, Podar T, Tuomilehto J (2005) Cumulative incidence of type 1 diabetes in 10,168 siblings of Finnish young-onset type 1 diabetic patients. Diabetes 54:563-569

45. Lorenzen T, Pociot F, Hougaard P, Nerup J (1994) Long-term risk of IDDM in first-degree relatives of patients with IDDM. Diabetologia 37:321-327

46. Warram JH, Krolewski AS, Gottlieb MS, Kahn CR (1984) Differences in risk of insulin-dependent diabetes in offspring of diabetic mothers and diabetic fathers. N Engl J Med 311:149-152

47. Lorenzen T, Pociot F, Stilgren L et al (1998) Predictors of IDDM recurrence risk in offspring of Danish IDDM patients. Danish IDDM Epidemiology and Genetics Group. Diabetologia 41:666-673

48. Harjutsalo V, Reunanen A, Tuomilehto J (2006) Differential transmission of type 1 diabetes from diabetic fathers and mothers to their offspring. Diabetes 55:1517-1524

49. Hemminki K, Li X, Sundquist J, Sundquist K (2009) Familial association between type 1 diabetes and other autoimmune and related diseases. Diabetologia 52:1820-1828

50. Bonifacio E, Pflüger M, Marienfeld S, Winkler C, Hummel M, Ziegler AG (2008) Maternal type 1 diabetes reduces the risk of islet autoantibodies: relationships with birthweight and maternal $\mathrm{HbA}_{1 \mathrm{c}}$. Diabetologia 51:1245-1252

51. Gillespie KM, Gale EA, Bingley PJ (2002) High familial risk and genetic susceptibility in early onset childhood diabetes. Diabetes $51: 210-214$

52. Redondo MJ, Yu L, Hawa M et al (2001) Heterogeneity of type I diabetes: analysis of monozygotic twins in Great Britain and the United States. Diabetologia 44:354-362

53. Harjutsalo V, Lammi N, Karvonen M, Groop PH (2010) Age at onset of type 1 diabetes in parents and recurrence risk in offspring. Diabetes 59:210-214

54. Tillil H, Köbberling J (1987) Age-corrected empirical genetic risk estimates for first-degree relatives of IDDM patients. Diabetes 36:93-99

55. Bleich D, Polak M, Eisenbarth GS, Jackson RA (1993) Decreased risk of type I diabetes in offspring of mothers who acquire diabetes during adrenarchy. Diabetes 42:1433-1439

56. Cardwell CR, Stene LC, Joner G et al (2008) Caesarean section is associated with an increased risk of childhood onset type 1 diabetes: a meta-analysis of observational studies. Diabetologia 51:726-735

57. Cardwell CR, Stene LC, Joner G et al (2010) Maternal age at birth and childhood type 1 diabetes: a pooled analysis of 30 observational studies. Diabetes 59:486-494

58. Cardwell CR, Stene LC, Joner G et al (2011) Birth order and childhood type 1 diabetes risk: a pooled analysis of 31 observational studies. Int J Epidemiol 40:363-374

59. Cardwell CR, Svensson J, Waldhoer T et al (2012) Interbirth interval is associated with childhood type 1 diabetes risk. Diabetes 61:702-707

60. Henry EB, Patterson CC, Cardwell CR (2011) A meta-analysis of the association between pre-eclampsia and childhood-onset type 1 diabetes mellitus. Diabet Med 28:900-905
61. McNamee MB, Cardwell CR, Patterson CC (2012) Neonatal jaundice is associated with a small increase in the risk of childhood type 1 diabetes: a meta-analysis of observational studies. Acta Diabetol 49:83-87

62. Stene LC, Barriga K, Norris JM et al (2004) Perinatal factors and development of islet autoimmunity in early childhood: the Diabetes Autoimmunity Study in the Young. Am J Epidemiol 160:3-10

63. Hummel M, Schenker M, Ziegler AG (2001) Influence of perinatal factors on the appearance of islet autoantibodies in offspring of parents with type 1 diabetes. Pediatr Diabetes 2:40-42

64. Struwe FE (1960) On the manifestation of diabetes mellitus in childhood (age of manifestation, maternal age at birth, familial diabetes). Monatsschr Kinderheilkd 108:487-490 [article in German]

65. Flood TM, Brink SJ, Gleason RE (1982) Increased incidence of type I diabetes in children of older mothers. Diabetes Care 6:571-573

66. Deschamps I, Lestradet H, Busson M, Hors J (1984) Evaluation of recurrence risk in siblings of diabetic children: importance of age and birth order in relation to HLA genotypes. Diabetes Res $1: 125-130$

67. Dahlquist G, Källén B (1992) Maternal-child blood group incompatibility and other perinatal events increase the risk for earlyonset type 1 (insulin-dependent) diabetes mellitus. Diabetologia 35:671-675

68. Ng SF, Lin RC, Laybutt DR, Barres R, Owens JA, Morris MJ (2010) Chronic high-fat diet in fathers programs beta-cell dysfunction in female rat offspring. Nature 467:963-966

69. Carone BR, Fauquier L, Habib N et al (2010) Paternally induced transgenerational environmental reprogramming of metabolic gene expression in mammals. Cell 143:1084-1096

70. Strachan DP (1989) Hay fever, hygiene, and household size. BMJ 299:1259-1260

71. Bonifacio E, Warncke K, Winkler C, Wallner M, Ziegler AG (2011) Cesarean section and interferon-induced helicase gene polymorphisms combine to increase childhood type 1 diabetes risk. Diabetes 60:3300-3306

72. Dominguez-Bello MG, Costello EK, Contreras M et al (2010) Delivery mode shapes the acquisition and structure of the initial microbiota across multiple body habitats in newborns. Proc Natl Acad Sci USA 107:11971-11975

73. Stene LC, Thorsby PM, Berg JP et al (2006) The relation between size at birth and risk of type 1 diabetes is not influenced by adjustment for the insulin gene $(-23 \mathrm{HphI})$ polymorphism or HLA-DQ genotype. Diabetologia 49:2068-2073

74. Brown RJ, Rother KI (2008) Effects of beta-cell rest on beta-cell function: a review of clinical and preclinical data. Pediatr Diabetes 9:14-22

75. Pang TT, Narendran P (2008) Addressing insulin resistance in type 1 diabetes. Diabet Med 25:1015-1024

76. Robertson L, Harrild K (2010) Maternal and neonatal risk factors for childhood type 1 diabetes: a matched case-control study. BMC Publ Health 10:281

77. Marshall AL, Chetwynd A, Morris JA et al (2004) Type 1 diabetes mellitus in childhood: a matched case control study in Lancashire and Cumbria, UK. Diabet Med 21:1035-1040

78. Hjern A, Söderström U (2008) Parental country of birth is a major determinant of childhood type 1 diabetes in Sweden. Pediatr Diabetes 9:35-39

79. Ievins R, Roberts SE, Goldacre MJ (2007) Perinatal factors associated with subsequent diabetes mellitus in the child: record linkage study. Diabet Med 24:664-670

80. Rasmussen T, Witsø E, Tapia G, Stene LC, Rønningen KS (2011) Self-reported lower respiratory tract infections and development of islet autoimmunity in children with the type 1 diabetes highrisk HLA genotype: the MIDIA study. Diabetes Metab Res Rev 27:834-837 
81. Virtanen SM, Kenward MG, Erkkola M et al (2006) Age at introduction of new foods and advanced beta cell autoimmunity in young children with HLA-conferred susceptibility to type 1 diabetes. Diabetologia 49:1512-1521

82. Ng SP, Zelikoff JT (2007) Smoking during pregnancy: subsequent effects on offspring immune competence and disease vulnerability in later life. Reprod Toxicol 23:428-437

83. Joubert BR, Håberg SE, Nilsen RM et al (2012) $450 \mathrm{~K}$ Epigenome-wide scan identifies differential DNA methylation in newborns related to maternal smoking during pregnancy. Environ Health Perspect 120:1425-1431

84. Menser MA, Dods L, Harley JD (1967) A twenty-five-year follow-up of congenital rubella. Lancet 2:1347-1350

85. Forrest JM, Turnbull FM, Sholler GF et al (2002) Gregg's congenital rubella patients 60 years later. Med J Aust 177:664-667

86. Forrest JM, Menser MA, Burgess JA (1971) High frequency of diabetes mellitus in young adults with congenital rubella. Lancet 2:332-334

87. Gale EA (2008) Congenital rubella: citation virus or viral cause of type 1 diabetes? Diabetologia 51:1559-1566

88. Viskari H, Knip M, Tauriainen S et al (2012) Maternal enterovirus infection as a risk factor for type 1 diabetes in the exposed offspring. Diabetes Care 35:1328-1332

89. Lamb MM, Myers MA, Barriga K, Zimmet PZ, Rewers M, Norris JM (2008) Maternal diet during pregnancy and islet autoimmunity in offspring. Pediatr Diabetes 9:135-141

90. Virtanen SM, Uusitalo L, Kenward MG et al (2011) Maternal food consumption during pregnancy and risk of advanced betacell autoimmunity in the offspring. Pediatr Diabetes 12:95-99

91. Stene LC, Ulriksen J, Magnus P, Joner G (2000) Use of cod liver oil during pregnancy associated with lower risk of type I diabetes in the offspring. Diabetologia 43:1083-1092

92. Sørensen IM, Joner G, Jenum PA, Eskild A, Stene LC (2012) Serum long chain n-3 fatty acids (EPA and DHA) in the pregnant mother are independent of risk of type 1 diabetes in the offspring. Diabetes Metab Res Rev 28:431-438

93. Oresic M, Simell S, Sysi-Aho M et al (2008) Dysregulation of lipid and amino acid metabolism precedes islet autoimmunity in children who later progress to type 1 diabetes. J Exp Med 205:2975-2984

94. Erkkola M, Nwaru BI, Viljakainen HT (2011) Maternal vitamin $\mathrm{D}$ during pregnancy and its relation to immune-mediated diseases in the offspring. Vitam Horm 86:239-260

95. Zehnder D, Evans KN, Kilby MD et al (2002) The ontogeny of 25-hydroxyvitamin $\mathrm{D}_{3} 1 \alpha$-hydroxylase expression in human placenta and decidua. Am J Pathol 161:105-114

96. Marjamäki L, Niinistö S, Kenward MG et al (2010) Maternal intake of vitamin D during pregnancy and risk of advanced beta cell autoimmunity and type 1 diabetes in offspring. Diabetologia 53:1599-1607

97. Sørensen IM, Joner G, Jenum PA, Eskild A, Torjesen PA, Stene LC (2012) Maternal serum levels of 25-hydroxy-vitamin D during pregnancy and risk of type 1 diabetes in the offspring. Diabetes 61:175-178

98. Miettinen ME, Reinert L, Kinnunen L et al (2012) Serum 25hydroxyvitamin $\mathrm{D}$ level during early pregnancy and type 1 diabetes risk in the offspring. Diabetologia 55:1291-1294
99. The TRIGR Study Group (2011) The Trial to Reduce IDDM in the Genetically at Risk (TRIGR) study: recruitment, intervention and follow-up. Diabetologia 54:627-633

100. Knip M, Virtanen SM, Seppa K et al (2010) Dietary intervention in infancy and later signs of beta-cell autoimmunity. N Engl J Med 363:1900-1908

101. Vaarala O, Ilonen J, Ruohtula T et al (2012) Removal of bovine insulin from cow's milk formula and early initiation of beta-cell autoimmunity in the FINDIA pilot study. Arch Pediatr Adolesc Med 166:608-614

102. Giulietti A, Gysemans C, Stoffels K et al (2004) Vitamin D deficiency in early life accelerates type 1 diabetes in non-obese diabetic mice. Diabetologia 47:451-462

103. Hawa MI, Valorani MG, Buckley LR et al (2004) Lack of effect of vitamin D administration during pregnancy and early life on diabetes incidence in the non-obese diabetic mouse. Horm Metab Res 36:620-624

104. Oge A, Isganaitis E, Jimenez-Chillaron J et al (2007) In utero undernutrition reduces diabetes incidence in non-obese diabetic mice. Diabetologia 50:1099-1108

105. Maloney S, Smith A, Furst DE et al (1999) Microchimerism of maternal origin persists into adult life. J Clin Invest 104:41-47

106. Mold JE, Michaelsson J, Burt TD et al (2008) Maternal alloantigens promote the development of tolerogenic fetal regulatory $\mathrm{T}$ cells in utero. Science 322:1562-1565

107. Nelson JL, Gillespie KM, Lambert NC et al (2007) Maternal microchimerism in peripheral blood in type 1 diabetes and pancreatic islet $\beta$ cell microchimerism. Proc Natl Acad Sci U S A 104:1637-1642

108. vanZyl B, Planas R, Ye Y et al (2010) Why are levels of maternal microchimerism higher in type 1 diabetes pancreas? Chimerism $1: 45-50$

109. MacFarlane AJ, Strom A, Scott FW (2009) Epigenetics: deciphering how environmental factors may modify autoimmune type 1 diabetes. Mamm Genome 20:624-632

110. Hochberg Z, Feil R, Constancia M et al (2011) Child health, developmental plasticity, and epigenetic programming. Endocr Rev 32:159-224

111. Khulan B, Cooper WN, Skinner BM et al (2012) Periconceptional maternal micronutrient supplementation is associated with widespread gender related changes in the epigenome: a study of a unique resource in the Gambia. Hum Mol Genet 21:2086-2101

112. Relton CL, Davey SG (2010) Epigenetic epidemiology of common complex disease: prospects for prediction, prevention, and treatment. PLoS Med 7:e1000356

113. Rakyan VK, Down TA, Balding DJ, Beck S (2011) Epigenomewide association studies for common human diseases. Nat Rev Genet 12:529-541

114. Rakyan VK, Beyan H, Down TA et al (2011) Identification of type 1 diabetes-associated DNA methylation variable positions that precede disease diagnosis. PLoS Genet 7:e1002300

115. Stene LC, Rønningen KS, Undlien DE, Joner G (2011) Does the relative risk for type 1 diabetes conferred by HLA-DQ, INS, and PTPN22 polymorphisms vary with maternal age, birth weight, or cesarean section? Pediatr Diabetes 12:91-94 